\title{
An Utility Application for Circular-Slide Wave Energy Converter
}

\author{
Deguang $\mathrm{Li}^{1,}$, Shuqin Liu ${ }^{2, \mathrm{~b}}$, H.Ming Chen ${ }^{3, \mathrm{c}}$ \\ ${ }^{1}$ School of Electrical Engineering, Shandong University, Jinan, Shandong, China \\ ${ }^{2}$ School of Electrical Engineering, Shandong University, Jinan, Shandong, China \\ ${ }^{3}$ Wave Energy Technologies, Albany, NY, USA \\ azxning@sdu.edu.cn, ${ }^{\mathrm{b}}$ Ishuqin@sdu.edu.cn, ${ }^{\mathrm{c}} \mathrm{hm}$ chen@verizon.net
}

Keywords: wave energy converter, sliding mass, circular track, artificial spring, utility application,magnetic suspension

Abstract. A Brazil near-shore wave energy converter uses a large float and a long arm to drive a pump-turbine-generator system on land. This paper proposes to convert the float into a CircularSlide Wave Energy Converter with on-board power generating equipment.

\section{Introduction}

Proposed in references [1, 2] was a wave energy converter concept with a mass that slides in a circular track under gravity in response to wave-induced buoy pitch/roll, as illustrated in Figure 1. The concept is called Circular-Slide WEC; its components including the sliding mass, circular sliding track, connecting arm, gearbox, generator, etc, are mounted inside a hermetically sealed box for protection from the harsh ocean environment.

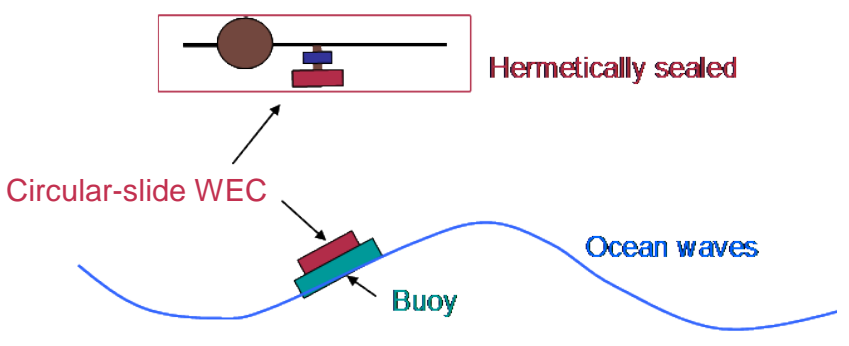

Fig. 1 - CS-WEC excited by pitch/roll of wave surface.

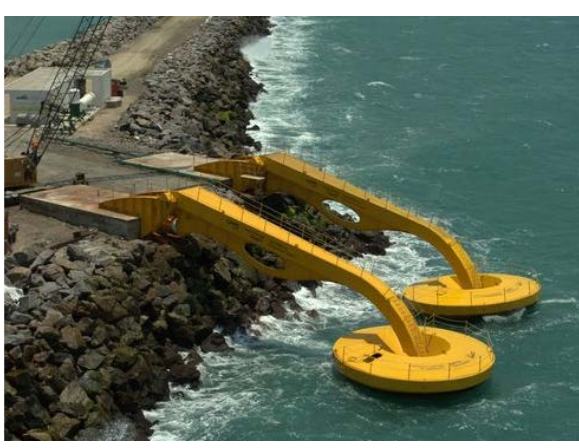

Fig. 2 - a Brazil WEC system.

The CS-WEC includes an artificial spring created by feedback control of the sliding mass angle. This spring together with the circular track supporting the weight of the sliding mass, eliminates the mechanical spring problems associated with the conventional WEC excited by wave heaving motions. The artificial spring rate is on-line adjustable to make the system resonating with dominant wave frequency and harvesting power efficiently. In this paper, a potential utility application of this concept will be elaborated.

A Brazil wave energy converter development has been presented in a video of the following website

\section{http://www.youtube.com/watch?v=GA_UgVm9bvU}

The video shows a pair of large circular floats; each pivoted at the end of a long curved arm (see Figure 2). The waves lift and lower the arm, which drives a hydraulic pump at the other end of the arm and generates high pressure fluid. The fluid turns an impulse turbine and generates electrical power.

Corresponding author: Shuqin Liu, Shandong university.

In additional to up and down motions, the video showed that the floats also roll and pitch as they pivot at the arm ends. Gagging from the relative sizes of people working on the float, the float diameter was estimated to be about $10 \mathrm{~m}$. This prompted the idea: 
To replace each float with a same-sized CS-WEC, Similar amount of power may be generated without the need of the large arms and pump-turbine-generator facility on land.

\section{Utility Application Concept}

Figure 3 elaborates the idea in more details. Each CS-WEC will be installed close to shore, such as shown in the video. It will be designed to have enough buoyancy force to support its own weight. It is fixed at an off-shore location by using an anchored post, or other similar sea floor fixation methods. It will float up and down as tides come and go. It rolls and pitches with rushing in waves. The rolling and pitching motions will generate power by the CS-WEC. This is opposite to the Brazil WEC, which generate power using the float up and down or heaving motions.

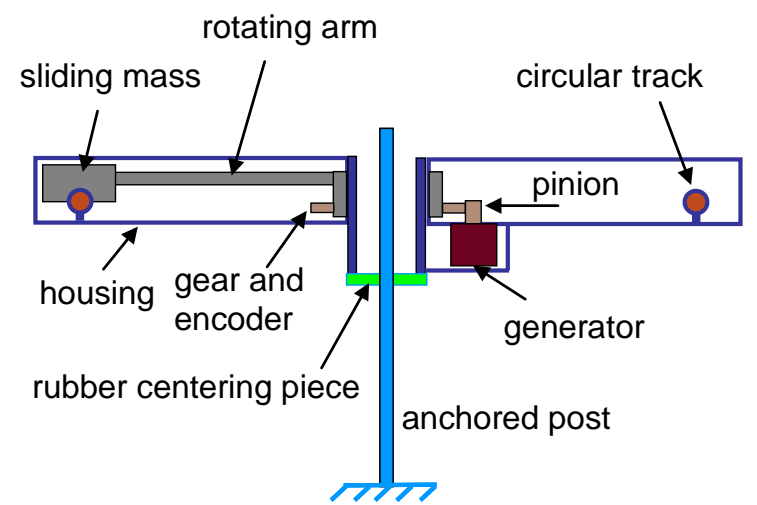

Fig. 3 - a CS-WEC set-up near shoreline.

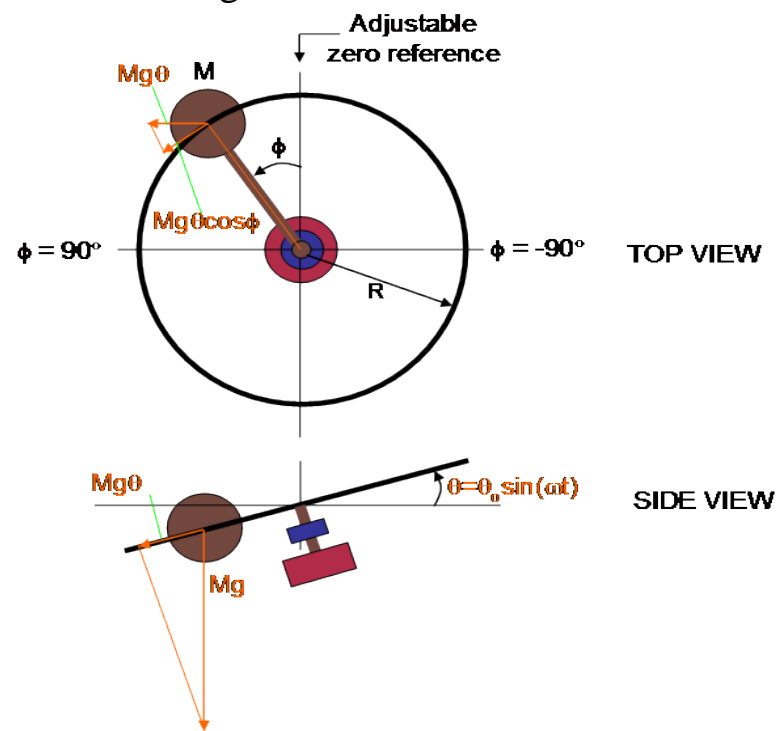

Fig. 4 - Relevant parameters of a circular-slide WEC.

\section{Dynamic Model}

As the CS-WEC housing tilts on wave surface, the sliding mass would slide on the circular track due to gravity. The associated force diagram is presented in Figure 4. Note that the pitch axis is assumed at $\phi$ equal to zero degree. The sliding mass and rotating arm turn the generator through a gear box. The system torsional dynamics may be represented by the diagram of Figure 5 . The speed increaser function is simply represented by a gear and a pinion. The rotating arm drives the gear and the pinion drives the generator rotor.

Figure 5 also shows a torsional spring grounded on the CS-WEC housing, which is relatively massive and with water drag. The generator output is represented by a torsional damping coefficient $\mathrm{B}$ to ground. The generator is at a higher speed with displacement, $\beta$. Neglecting the flexibility and polar moment of inertias of the gear box components, the equation of motion of a CS-WEC is:

$$
\left(M R^{2}+r^{2} I_{p}\right) \frac{d^{2} \phi}{d t^{2}}+r^{2} B \frac{d \phi}{d t}+K \phi=M g \sin (\theta) \cos (\phi) R
$$

Where

$\phi=$ sliding mass angular displacement on track, rad

$t=$ time, $\mathrm{s}$

$M=$ sliding mass, $\mathrm{kg}$

$R=$ circular track radius, $\mathrm{m}$

$B=$ equivalent damping coefficient of power output, Nm-s/rad

$K=$ artificial torsional spring constant from feedback control, $\mathrm{Nm} / \mathrm{rad}$

$r=\mathrm{R}$-gear/R-pinion = gear ratio

R-gear, R-pinion $=$ pitch radius of gear and pinion, respectively, $\mathrm{m}$

$I_{p}=$ polar moment of inertia of generator rotor, $\mathrm{kg}-\mathrm{m}^{2}$ 
$g$ = gravitational constant $=9.81 \mathrm{~m} / \mathrm{s}^{2}$

$\boldsymbol{\theta}=\boldsymbol{\theta}_{\boldsymbol{o}} \sin (\omega t)=$ instantaneous buoy incline angle, rad

$\omega=2 \pi / T=$ dominant wave frequency, $\mathrm{rad} / \mathrm{s}$

$T=$ dominant wave period, $\mathrm{s}$

$\theta_{o}=(H / 2)(2 \pi / \lambda)=0.707 H / T=$ buoy incline angle, $\mathrm{rad}$

$H=$ significant wave height, $\mathrm{m}$

$\lambda=\sqrt{g h} T=$ shallow water wave length [3], $\mathrm{m}$

$h=$ water depth, $\mathrm{m}$

The generator rotor contribution to the system polar moment of inertia is $r^{2} I_{p}$, which can be significant for large gear ratio $r$. This part of inertia tends to slow down the system and results in lower power harvest.

\section{Generator Sizing}

For the CS-WEC utility application, a permanent magnet generator was sized for $10 \mathrm{kw}$ at 600rpm and 200V. The generator has a lamination pattern shown in Figure 6 with a stator OD of $500 \mathrm{~mm}$, a rotor OD of $300 \mathrm{~mm}$ and a stack length of $500 \mathrm{~mm}$.

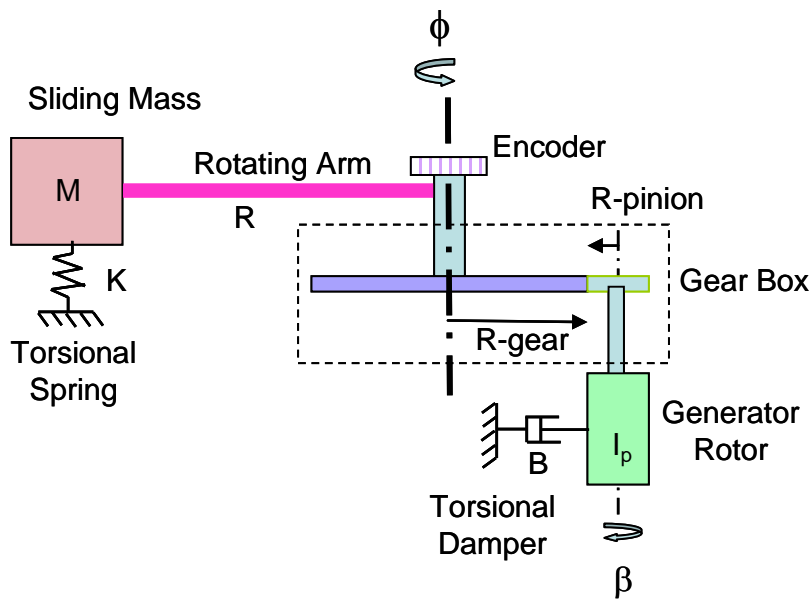

Fig. 5 - torsional dynamic model.

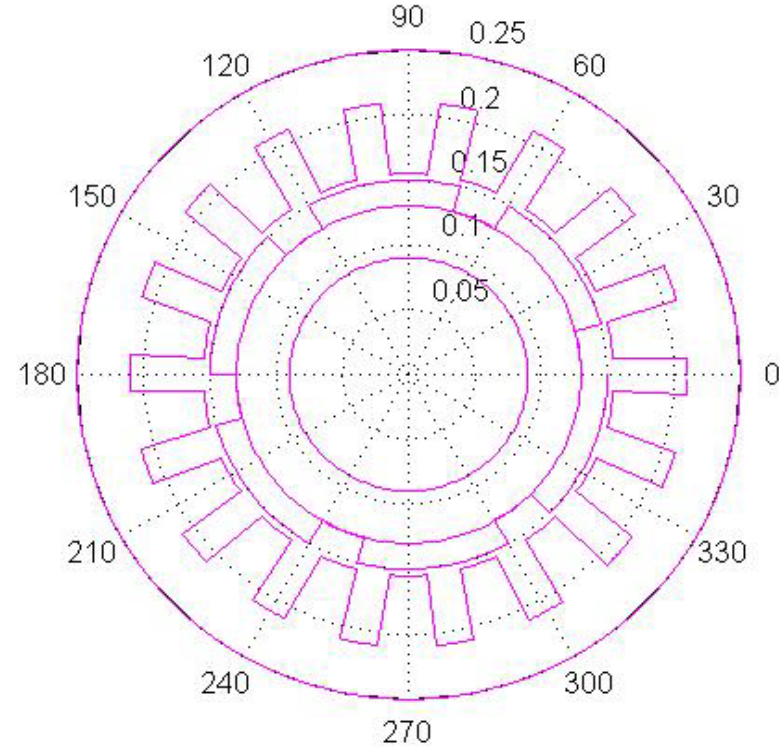

Fig. 6 - generator lamination pattern.

It has 3 phases, 18 coil slots and 6 magnets on rotor. To make the generator a low power consumption device, it has to accommodate enough copper wires with low resistance. At a low wave period of 5s, the sliding mass will slide back and forth at $0.2 \mathrm{~Hz}$ or $12 \mathrm{rpm}$. To achieve the generator speed of 600rpm, the gear box speed ratio has to be 50. Since the generator rotor has diameter of $0.3 \mathrm{~m}$ and a length of $0.5 \mathrm{~m}$, the equivalent generator rotor polar moment of inertia is significantly large and estimated to be:

$$
\mathrm{r}^{2} \mathrm{I}_{\mathrm{p}}=50^{2}\left(\pi \mathrm{D}^{4} \mathrm{~L} \rho / 32\right)=7800 \mathrm{~kg}-\mathrm{m}^{2}
$$

For lamination density $\rho=7850 \mathrm{~kg} / \mathrm{m}^{3}$. The generator torque constant and phase resistance were estimated to be $8.6 \mathrm{Nm} / \mathrm{A}$ and $0.64 \times 10^{-2} \mathrm{ohm}$, respectively. These parameters will be used for calculating the power consumption for the artificial spring motoring function performed in the generator. 


\section{Power Estimation}

Assuming the sliding mass of $1000 \mathrm{~kg}$ and a track radius of $5 \mathrm{~m}$, the CS-WEC power was estimated using a Matlab Simulink program based on equation (1), and the result is presented in Figure 7.

The net power was calculated to be $10.1 \mathrm{kw}$ for roll/pitch wave amplitude of $25^{\circ}$ at a wave period of $5 \mathrm{~s}$ as shown by the "scope" for "theta". The sliding mass swings back and forth with $\pm 90^{\circ}$ (see scope for PHI), indicating the CS-WEC operates at its maximum power condition [1, 2]. The artificial spring (eSpring) consumes a tolerable amount of 545w. The damping ratio in Figure 7 was based on the total polar moment of inertia and system the resonant frequency at $2 \pi / 5 \mathrm{rad} / \mathrm{s}$. The system was made to resonate at this frequency by the artificial spring.

The European ocean energy report [4] has revealed a WEC type called "rotating mass". Similar to CS-WEC, it utilizes the wave pitch and roll motions of a floating housing. Inside the floating housing, an eccentric mass rotates and drives an electrical generator. A prototype animation demonstration of the "rotating-mass" (http://www.wello.eu/penguin.php) showed the eccentric mass rotates in full circles. The power control appeared without using an artificial spring. To show the spring effect in our case, the power harvest without using the spring has been calculated and the result presented in Figure 8.

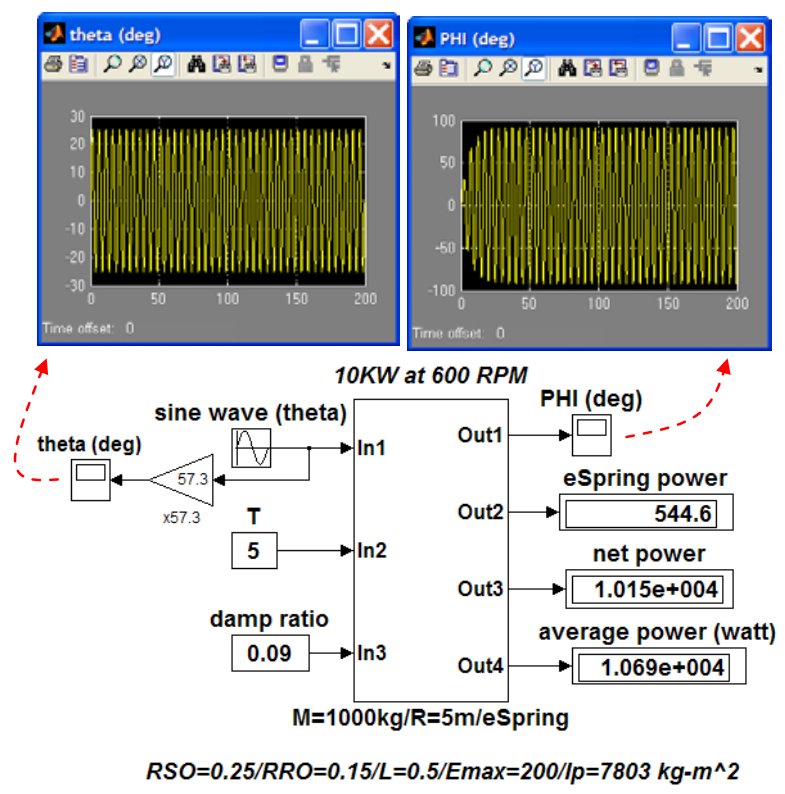

Fig. 7 - CS-WEC power for $M=1000 \mathrm{~kg}$ and $\mathrm{R}=5 \mathrm{~m}$ with spring.

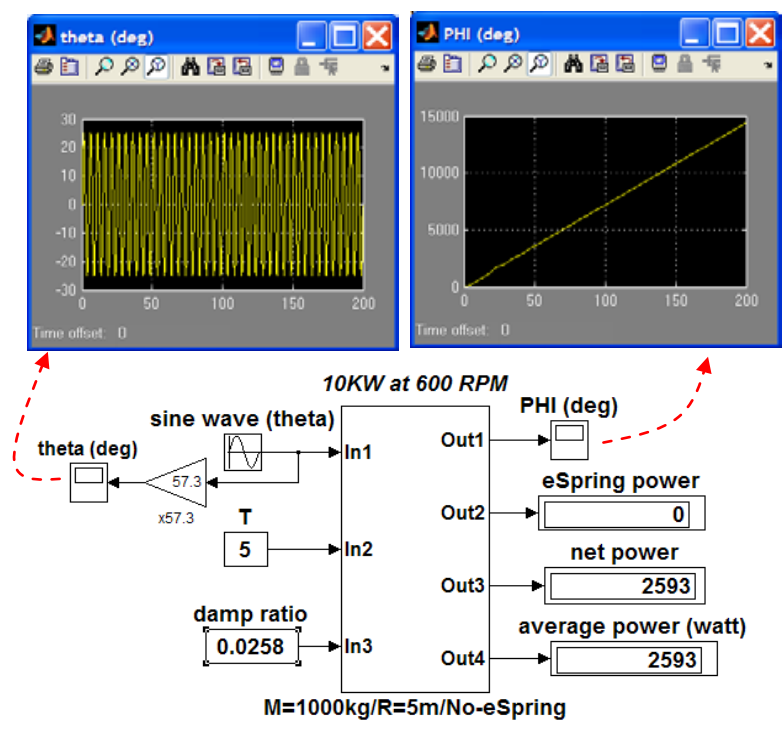

$R S O=0.25 / R R O=0.15 / L=0.5 / E \max =200 / \mathrm{lp}=7803 \mathrm{~kg}-\mathrm{m}^{\wedge} 2 / \mathrm{NoK}$

Fig. 8 - CS-WEC power for $\mathrm{M}=1000 \mathrm{~kg}$ and $\mathrm{R}=5 \mathrm{~m}$ without spring.

The maximum power without using the spring is about a quarter of that using the spring, or $2.6 \mathrm{kw}$. The sliding mass in CS-WEC moves in circles when the damping ratio is less than and equal to 0.026. This is indicated by the straight line (accumulated sliding angle) on the scope picture. Above the damping ratio, the sliding mass will stop moving in circles and the power becomes insignificant.

\section{Magnetic Levitation of Sliding Mass}

Note that the block sizes of the $1000 \mathrm{~kg}$ sliding mass made of iron is approximately $350 \mathrm{~mm} \mathrm{x}$ $350 \mathrm{~mm} \times 1 \mathrm{~m}$. It extends an angle on the track about 12 degrees. Since it is a heavy weight, we have considered magnetic suspension of the weight on track.

Figure 9 presents a maglev concept; it includes:

- a circular sliding track with a T-shaped cross-section,

- a vertical active magnetic bearing (AMB) for supporting the weight of the sliding mass,

- a radial AMB to keep the sliding mass from touching the track, and 
- two sets of touch-down roller bearings, one for vertical and the other for radial safety.

To save power, the AMB should apply permanent magnet bias. For stability of the mass being supported, there should be two independent AMBs (one at the front as shown and the other not shown in the back). The AMBs need power on the rotating frame. This is an added complexity.

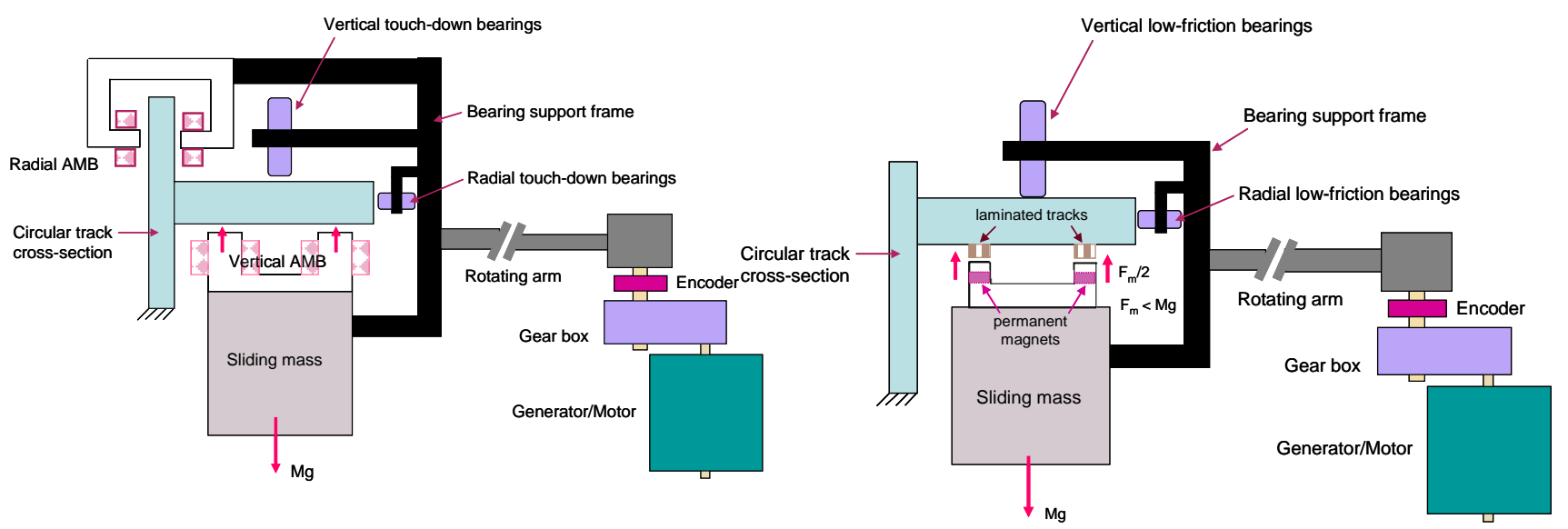

Fig. 9 - sliding-mass magnetic levitation concept.

Fig. 10 - using permanent magnets to reduce mechanical bearing loads.

A more plausible approach would be to use low-friction mechanical bearings with reduced loads. Figure 10 presents a concept how to reduce the vertical mechanical bearing load using permanent magnets. Most of the sliding mass weight is carried by the circular tracks using permanent magnet biased poles. The tracks are laminated to reduce eddy-current loss. A small portion of the weight is carried by the mechanical bearings for long service live. Note that the vertical magnetic poles work also as passive bearings in the radial direction (due to reluctance centering effect) and they assist the mechanical radial bearing.

\section{Summary and Conclusions}

In conclusion, the Brazil WEC installed by sea shore with a large float driving a hydraulic power system has prompted an idea that a CS-WEC with the size similar to the float may generate similar amount of wave power. This approach would eliminate the need of the large arm and power equipment on shore. Initial sizing estimation indicated that a CS-WEC with 5m-radius track and $1000 \mathrm{~kg}$ sliding mass can generate $10 \mathrm{kw}$ with $25^{\circ}$ roll $/$ pitch wave amplitude at a period of 5 seconds. To reduce vertical mechanical bearing loads due to the sliding-mass weight, passive permanent magnet biased poles are proposed to carry most of the weight under the circular sliding track. These poles also provide radial stiffness assisting the radial mechanical bearing.

\section{Acknowledgment}

THIS PAPER IS SUPPORTED BY 2013 INTERNATIONAL CORPORATION RESEARCH FUND OF JiNAN, CHINA, No. 201305057

\section{References}

[1] Chen, H.M. and DelBalzo, D.R., "Circular-slide wave energy converter," Proceedings of Ocean $\begin{array}{lllll}\text { Waves Workshop, New } & \text { Orleans } & 28 & \text { February }\end{array}$ (http://scholarworks.uno.edu/oceanwaves/2013).

[2] Chen, H.M. and DelBalzo, D.R., "Circular-Slide Wave Energy Converter in Random Waves," presented at Oceans’13, MTS/IEEE San Diego, 23-26 September, 2013. 
[3] McCormick, M. E., Ocean Wave Energy Conversion, Dover Publication Inc., 2007, Chapter 2.

[4] SI Ocean report, Ocean Energy: State of the Art, Dec, 2012, pages, 15, 16 and 30 (http://www.emec.org.uk/marine-energy/wave-devices/).

[5] Cheung, J.T. \& Childress, E.F. III, Ocean Wave Energy Harvesting, DARPA Phase 3 Final Report, Teledyne Scientific \& Imaging, April 2008. 